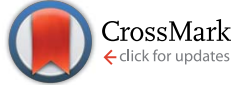

Cite this: RSC Adv., 2017, 7, 2388

Received 27th October 2016 Accepted 24th November 2016

DOI: 10.1039/c6ra25892a

www.rsc.org/advances

\section{Vanadium oxide-based photochromic composite film}

\author{
Hidetoshi Miyazaki, ${ }^{* a}$ Takahiro Matsuura ${ }^{a}$ and Toshitaka Ota ${ }^{b}$ \\ $\mathrm{V}_{2} \mathrm{O}_{5}$-based composite films were fabricated using peroxo-iso-poly vanadic acid as the filler and \\ transparent urethane resin as the matrix. The size of the $\mathrm{V}_{2} \mathrm{O}_{5}$ particles in the films was around 60- \\ $80 \mathrm{~nm}$ and the fabricated composite films exhibited photochromic properties when irradiated with \\ ultraviolet (UV) light. The composite films displayed multichromism (yellow $\leftrightarrow$ green $\leftrightarrow$ pale blue) under \\ UV irradiation. The absorption edge of the films shifted to lower wavelengths (Bürstein Moss effect) with \\ the increase of the coloring degree of the films. Almost all the colors of the composite film bleached \\ when placed in a dark room.
}

\section{Introduction}

Amorphous and crystalline $\mathrm{V}_{2} \mathrm{O}_{5}$ films are amongst the most widely investigated materials for electrochromic devices, ${ }^{\mathbf{1 - 3}}$ lithium ion batteries, ${ }^{4,5}$ chemical gas sensing, ${ }^{6,7}$ and photochromic device applications. ${ }^{\mathbf{8} 9}$ Electrochromism or photochromism of $\mathrm{V}_{2} \mathrm{O}_{5}$ is achieved by changing the valency of vanadium in the $\mathrm{V}_{2} \mathrm{O}_{5}$ host, using either an electrochemical or a photochemical electron transfer reaction. Thus, $\mathrm{V}_{2} \mathrm{O}_{5}$ can be used in display devices or smart windows that are activated photochemically or electrochemically.

Previously, we fabricated $\mathrm{WO}_{3}$ (ref. 10 and 11) and $\mathrm{MoO}_{3}$ (ref. 12) based photochromic composite films with rapid coloring and bleaching properties. The photochromism of the films was a direct result of the presence of sub-nanometer sized $\mathrm{WO}_{3}$ and $\mathrm{MoO}_{3}$ particles embedded in the resin matrix. In order to embed the nanoparticles in the matrix, we used tungsten or molybdenum peroxo-isopoly acid as the starting materials because of their solubility in $\mathrm{H}_{2} \mathrm{O}$ or alcohol and combined these with the transparent resin. It is assumed that by a similar method, a photochromic composite film of vanadium oxide can be created using vanadium oxide nanoparticles. Peroxo-iso-poly vanadic acid (V-IPA), which is readily formed when $\mathrm{H}_{2} \mathrm{O}_{2}$ reacts with vanadium metal, is highly soluble in water..$^{\mathbf{1 3 , 1 4}}$ Therefore, we expect to fabricate vanadium oxide-based photochromic composite films, containing sub nanometer size particles, using V-IPA.

In this study, we have fabricated $\mathrm{V}_{2} \mathrm{O}_{5}$-based composite films using V-IPA and transparent urethane resin and evaluated their photochromic properties.

${ }^{a}$ Interdisciplinary Graduate School of Science and Engineering, Shimane University, 1060, Nishikawatsu, Matsue, Shimane, 690-8504, Japan. E-mail: miya@riko. shimane-u.ac.jp

${ }^{b}$ Ceramic Research Laboratory, Nagoya Institute of Technology, 10-6-29, Asahigaoka, Tajimi, Gifu, 507-0071, Japan

\section{Experimental procedure}

Vanadium powder (1.0 g, Wako, Osaka, Japan) was mixed with $30 \%$ aq. $\mathrm{H}_{2} \mathrm{O}_{2}$ solution $(100 \mathrm{~mL})$ in an ice bath for $15 \mathrm{~h}$. After reaction, the excess $\mathrm{H}_{2} \mathrm{O}_{2}$ was removed catalytically using Pt nets. The resulting orange solution was dried using a rotary evaporator with $60 \mathrm{rpm}$, placed in a water bath maintained at $40{ }^{\circ} \mathrm{C}$ for $1 \mathrm{~h}$, to obtain V-IPA powder.

V-IPA powder was then dissolved in ion-exchanged water to form a vanadium solution, with a final concentration of $0.2 \mathrm{M}$. The obtained solution $(0.15 \mathrm{~mL})$ was mixed with $3.2 \mathrm{~g}$ of liquid urethane resin (M-40; Asahi Kasei Chemicals Corp., Japan). The liquid urethane resin was used as the matrix material in the synthesis of the composite films, and it the resin was cured by irradiation with UV light. The precursor mixture (slurry state) was degassed at $1 \mathrm{kPa}$ for $60 \mathrm{~min}$. The precursor was first placed between two glass slides such that a $150 \mu \mathrm{m}$ thick film could be formed and irradiated with UV light for $5 \mathrm{~min}$ before removing it from the glass. The resulting films were pale blue in color because of the effects of the UV radiation and hence, the composite films were placed in a dark room for three days for clarification.

The structure of the V-IPA powder was characterized by X-ray diffraction (XRD) using a Rigaku Miniflex with $\mathrm{CuK} \alpha$ radiation. The microstructure and the crystallographic structure of the particles in the composite film was characterized by transmission electron microscopy (TEM, EM-002B; Topcon Corp., Japan) and selected area electron diffraction (SAED, ibid.). The photochromic properties of the films were evaluated at room temperature with a UV-Vis spectrophotometer (UV-1600; Shimadzu Corp., Japan). Throughout the investigation, a $1 \mathrm{~kW}$ high-pressure $\mathrm{Hg}$ lamp was used for curing the resin and for color manipulation of the composite films. The coloring properties of the films were evaluated by UV irradiation, while the film bleaching properties were observed by placing the films in a darkened room. 


\section{Results and discussions}

A direct reaction between vanadium metal and hydrogen peroxide was carried out and the resulting precursor solution was dried by evaporation to obtain $\mathrm{V}_{2} \mathrm{O}_{5}$ powder. Fig. 1 depicts the XRD pattern of the resulting powder. The resulting powder displayed (110), (410), (310) and (600) planes of the $\mathrm{V}_{2} \mathrm{O}_{5}$ peaks, thus exhibiting only the $(h k 0)$ planes. The results were in good agreement with previous studies of V-IPA. ${ }^{13}$ The V-IPA $\left(2 \mathrm{D}-\mathrm{V}_{2} \mathrm{O}_{5}\right)$ powder, thus synthesized, was further used in our study.

Vanadium oxide-based composite films were fabricated using the synthesized V-IPA and the cured urethane resin. Fig. 2 shows the TEM bright field image and the selected area electron diffraction (SAED) image of a composite film. The $\mathrm{V}_{2} \mathrm{O}_{5}$ particle size in the composite film was about $60-80 \mathrm{~nm}$ and the particles were dispersed homogeneously throughout the film. Using the electron diffraction pattern, the crystallographic structure of the particles in the resulting composite film were confirmed to be $\mathrm{V}_{2} \mathrm{O}_{5}$. Photochromic properties of the films were evaluated by UV irradiation. Fig. 3 illustrates the UV-Vis spectra of the composite film before and after UV irradiation and the inset photographs shows the overview of the same. From the overview, it is evident that the initial color of the resultant film was yellow, which color was close to $\mathrm{V}_{2} \mathrm{O}_{5}$ film. ${ }^{2,3}$ However, the color of the film changed gradually from yellow to green to pale blue after exposure to UV light and had a weak, but broad absorption spectrum with peak at around $700 \mathrm{~nm}$. After $60 \mathrm{~min}$ of UV irradiation the film displayed a higher transmittance in the wavelength region of $1000-1100 \mathrm{~nm}$ than the film exposed to $10 \mathrm{~min}$ of UV irradiation. Though the colored film bleached when placed in a dark room, complete bleaching did not occur until $48 \mathrm{~h}$. In the previous investigation of $\mathrm{V}_{2} \mathrm{O}_{5}$ electrochromism, it was observed that the $\mathrm{V}_{2} \mathrm{O}_{5}$ film color changed from yellow $\sim$ green $\sim$ pale blue because of $\mathrm{Li}$ ion insertion ${ }^{3}$ and

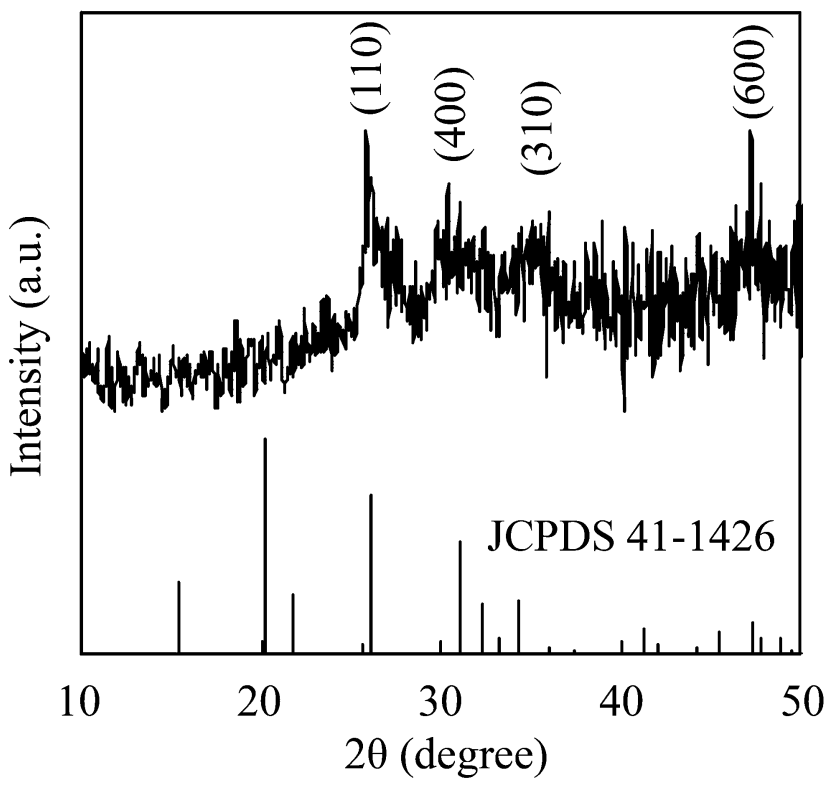

Fig. 1 The XRD pattern of the vanadium oxide-based powder.

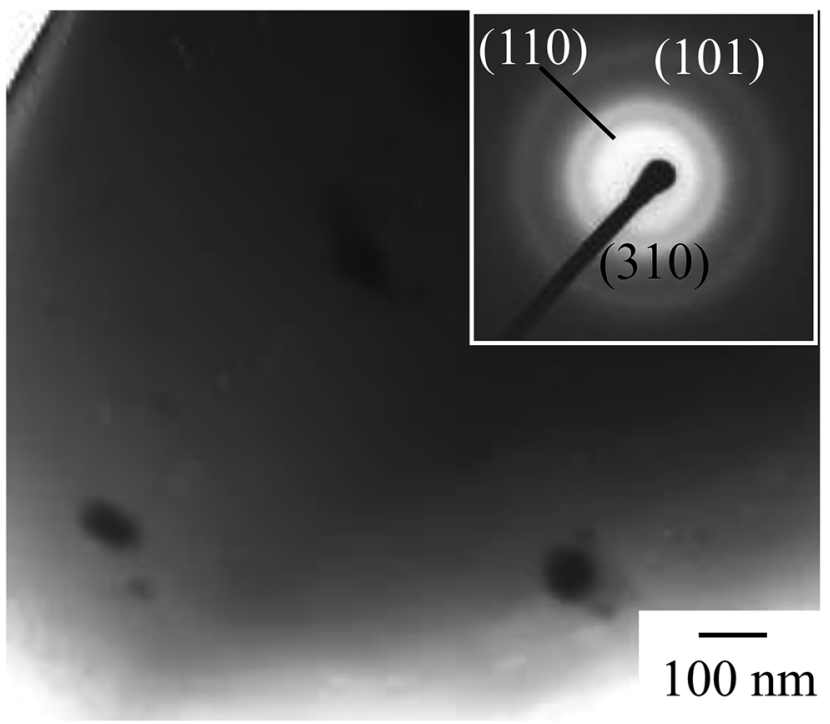

Fig. 2 The TEM image of the composite film.

the previous results of color changing on the $\mathrm{V}_{2} \mathrm{O}_{5}$ electrochromism agreed well with the present investigation. Significantly, the composite film in the present study showed a semireversible photochromic property, similar to the electrochromic $\mathrm{V}_{2} \mathrm{O}_{5}$ film.

With respect to the electrochromism of $\mathrm{V}_{2} \mathrm{O}_{5}$, vanadium valence is electrochemically reduced from " +5 " to " +4 " and thus the color change is attributed to this change in the valence state. Similar to the photochromism of $\mathrm{V}_{2} \mathrm{O}_{5}$, it assumed that change

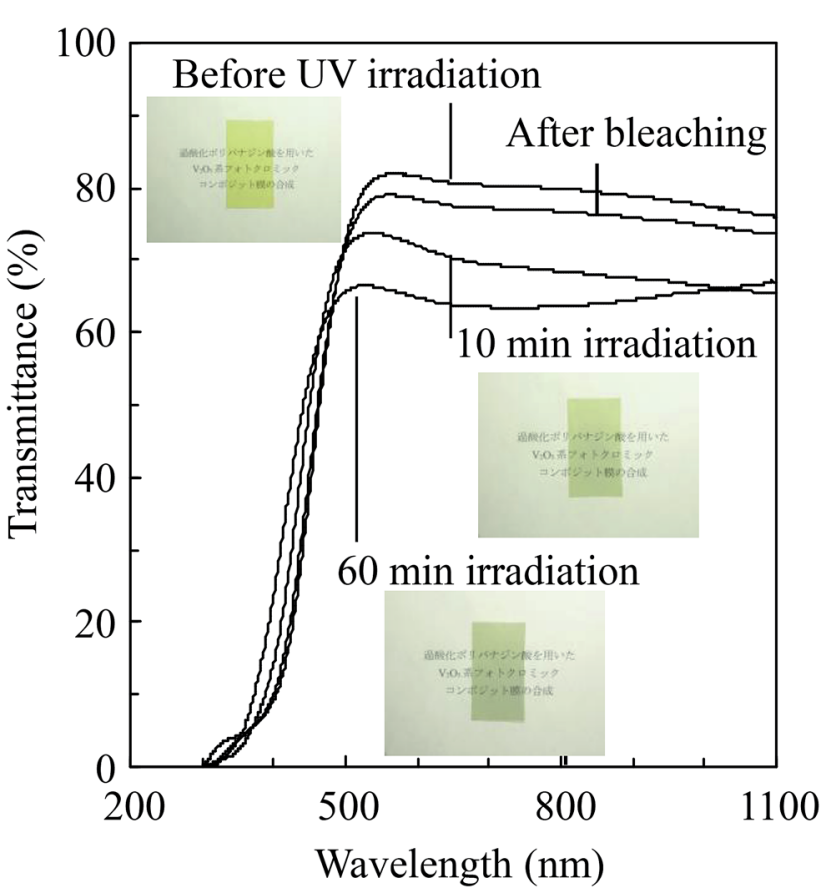

Fig. 3 The UV-Vis spectra of the composite films before UV-Vis irradiation, after UV-Vis irradiation and of the re-bleached film. Insets show the overview of the films. 
in the valence state of vanadium and the change in color of $\mathrm{V}_{2} \mathrm{O}_{5}$ were caused by UV irradiation. The exact photochromic mechanism has been previously reported with regard to $\mathrm{MoO}_{3}$-based composite films. ${ }^{12}$ Applying the similar theory to $\mathrm{V}_{2} \mathrm{O}_{5}$-based composite films; the photochromic mechanism can be explained as follows:

$$
\mathrm{V}_{2} \mathrm{O}_{5} \stackrel{h v}{\longrightarrow} \mathrm{V}_{2} \mathrm{O}_{5}^{*}+\mathrm{e}^{-}+\mathrm{h}^{+}
$$

$$
\begin{gathered}
\mathrm{h}^{+}+\mathrm{H}_{2} \mathrm{O} \text { (as precursor solvent) } \rightarrow \mathrm{H}^{+}+-\mathrm{OH} \\
\mathrm{V}_{2}^{5+} \mathrm{O}_{5} \text { (colored) }+x \mathrm{H}^{+}+x \mathrm{e}^{-} \text {(bleached) } \rightarrow \\
\mathrm{H}_{x} \mathrm{~V}_{2-x}{ }^{5+} \mathrm{V}_{x}^{4+} \mathrm{O}_{5} \text { (colored) }
\end{gathered}
$$

where, * represents exited state, $\mathrm{e}^{-}$is an electron, and $\mathrm{h}^{+}$is a hole. From Fig. 3, it is clear that the absorption edge of the film shifted to lower wavelengths following an increase in UV irradiation time. We estimated the optical band gap, $E_{\mathrm{g}}$, of the film using a Tauc plot, is as shown in Fig. 4. The $E_{\mathrm{g}}$ of the films before UV irradiation, after $10 \mathrm{~min}$ irradiation, and after $60 \mathrm{~min}$ irradiation were $2.52 \mathrm{eV}, 2.57 \mathrm{eV}$, and $2.61 \mathrm{eV}$, respectively. Increasing the UV irradiation time caused an increase in the $E_{\mathrm{g}}$ of the films (Bürstein Moss effect). However, in case of electrochromism of $\mathrm{V}_{2} \mathrm{O}_{5}$ with $\mathrm{Li}$ intercalation, an increase in the amount of intercalated $\mathrm{Li}$ caused an increase in the carrier concentration in $\mathrm{V}_{2} \mathrm{O}_{5}$, thus increasing the bandgap of $\mathrm{V}_{2} \mathrm{O}_{5}$ host (Bürstein Moss effect). ${ }^{15}$ It is assumed that the Bürstein Moss effect is also seen in the current study because there is an increase in the carrier concentration in $\mathrm{V}_{2} \mathrm{O}_{5}$ due to the generation of photo-induced electrons. For the electrochromism of $\mathrm{V}_{2} \mathrm{O}_{5}$ films, the intercalated cation quantity in the $\mathrm{V}_{2} \mathrm{O}_{5}$ host caused the transmittance in the near-IR region to increase or decrease suitably. ${ }^{16}$ The transmittance change in the near-IR region at 1000-1100 $\mathrm{nm}$ (see Fig. 3) in the present film was also assumed to vary due to increased charge density caused by long time UV irradiation.

In order to evaluate the coloring and bleaching property of the films, time dependent studies on transmittance of the

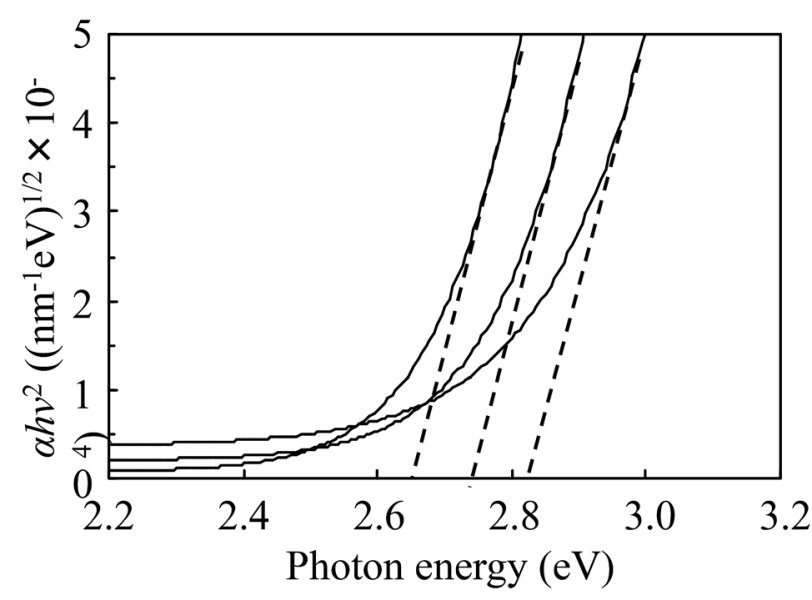

Fig. 4 Plot of $(\alpha h \nu)^{2}$ versus photon energy for the composite film. composite film were performed, as shown in Fig. 5. The colored films showed significant absorption around $700 \mathrm{~nm}$ and hence, transmittance at $700 \mathrm{~nm}$ was studied. Assuming the reaction to be of first order, the reaction rate constant $k$ can be estimated as follows:

$$
-\ln \left([A] /\left[A_{0}\right]\right)=k t,
$$

where $A_{0}$ is the initial absorbance, $t$ is the passing time and $A$ is the absorbance at time $t$. Fig. 6 shows a plot of $-\ln \left([A] /\left[A_{0}\right]\right)$ as a function of time. Plots for the coloring reaction were linear and the reaction rate constant of the composite film was calculated to be $0.084 \mathrm{~min}^{-1}$. However, plots for the bleaching reaction were nonlinear, and hence, were not first order reactions with a single rate determining step. The electron mobility in $\mathrm{V}_{2} \mathrm{O}_{5}$ clusters is assumed to be the rate-controlling factor, returning the electrons from $\mathrm{V}^{4+}$ to the matrix (hydroxyl function) and so on. However, the reaction constants of the bleached films could not be evaluated.

There have been few reports on the photochromism of $\mathrm{V}_{2} \mathrm{O}_{5}$ thin films or bulk ceramics. Nishio et al. reported the photochromism of $\mathrm{V}_{2} \mathrm{O}_{5}$ bulk ceramics that were colored by "Ar ion laser irradiation" and bleached by "oxidation at a high temperature of $400{ }^{\circ} \mathrm{C}$. ${ }^{8}$ Wan et al. fabricated $\mathrm{V}_{2} \mathrm{O}_{5}$ xerogel films by a sol-gel method; the film thickness was less than $10 \mu \mathrm{m}$. The $\mathrm{V}_{2} \mathrm{O}_{5}$ xerogel films exhibited photochromic property because of hydrogen atoms which were detached under the action of light from organic-molecules adsorbed on the "film surface". ${ }^{9}$ However, these reports do not describe the bleaching property. Remarkably, in this study, $130 \mu \mathrm{m}$ thick $\mathrm{V}_{2} \mathrm{O}_{5}$-based composite films with reversible photochromic properties were fabricated by just irradiating the films with UV light at room temperature. In addition, when the particle size in $\mathrm{WO}_{3}$ and $\mathrm{MoO}_{3}$-based composite film was in the order of sub nanometers, reversible photochromic properties were observed at room temperature. ${ }^{\mathbf{1 0 - 1 2}}$ Similarly, the presence of these nanometer size $\mathrm{V}_{2} \mathrm{O}_{5}$ is considered to be responsible for the photochromic property of the composite film, in the present study. Furthermore, other nano-composite film fabrication methods have

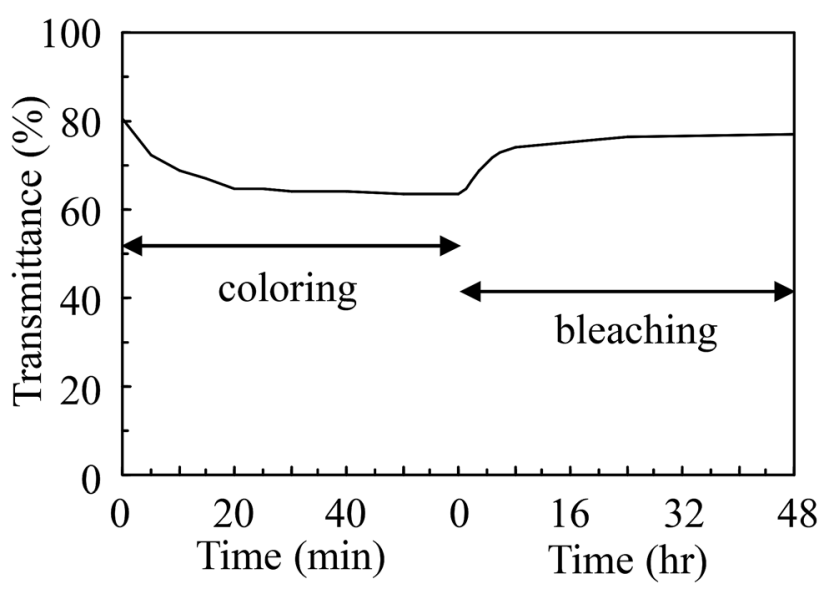

Fig. 5 The time dependence of transmittance change on coloring and bleaching of the composite film. 

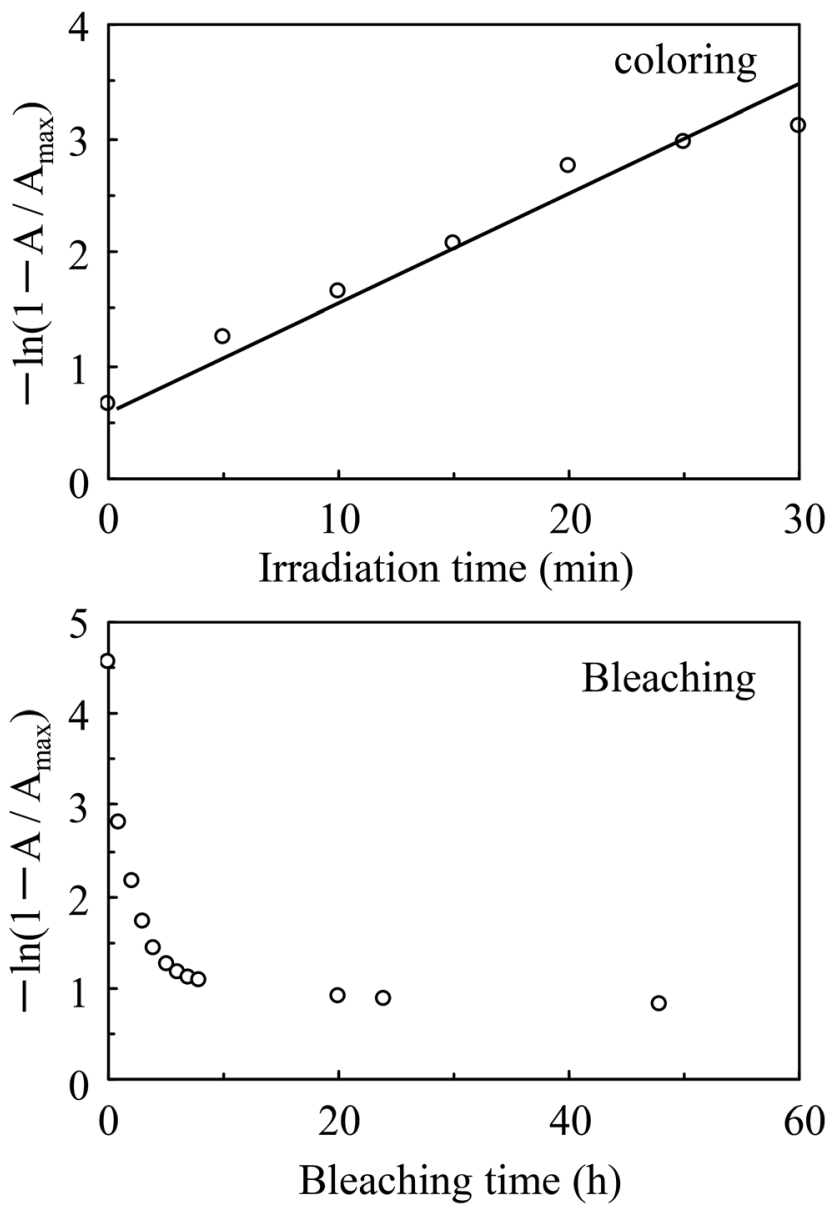

Fig. 6 The plots of $-\ln \left([A] /\left[A_{0}\right]\right)$ as a function of time.

been reported. ${ }^{17,18}$ We should elucidate the photochromic properties of $\mathrm{V}_{2} \mathrm{O}_{5}$ nano-composites fabricated by various methods in future research.

\section{Conclusions}

We fabricated vanadium oxide-based composite films with homogeneously dispersed sub-nanometer sized $\mathrm{V}_{2} \mathrm{O}_{5}$ particles. The composite films upon irradiation with UV light showed a broad absorption peak at $700 \mathrm{~nm}$. Furthermore, the optical band gap $\left(E_{\mathrm{g}}\right)$ of the film increased with increase in UV irradiation time because of the corresponding increase in carrier concentration. This increase in $E_{\mathrm{g}}$ is assumed to be due to the Bürstein Moss effect. Moreover, the colored films bleached when kept in the dark. In conclusion, we successfully fabricated vanadium oxide photochromic composite films using V-IPA and urethane resin.

\section{References}

1 A. Talledo and C. G. Granqvist, J. Appl. Phys., 1995, 77, 4655. 2 S. Krishnakumar and C. S. Menon, Phys Status Solidi, 1996, 153, 439.

3 Y. R. Lu, T. Z. Wu, C. L. Chen, D. H. Wei, J. L. Chen, W. C. Chou and C. L. Dong, Nanoscale Res. Lett., 2015, 10, 387.

4 G. P. Holland, J. L. Yarger, D. A. Buttry, F. Huguenin and R. M. J. Torresi, J. Electrochem. Soc., 2003, 150, A1718.

5 H. Yamada, K. Tagawa, M. Komatsu, I. Moriguchi and T. Kudo, J. Phys. Chem. C, 2007, 111, 8397.

6 W. Fergus, Sens. Actuators, 2007, 121, 652.

7 A. D. Raj, T. Pazhanivel, P. S. Kumar, D. Mangalaraj, D. Nataraj and N. Ponpandian, Curr. Appl. Phys., 2010, 10, 531.

8 S. Nishio and M. Kakihana, Chem. Mater., 2002, 14, 3730.

9 Y. Wang, L. Pan, Y. Li and A. I. Gavrilyuk, Appl. Surf. Sci., 2014, 314, 384.

10 H. Miyazaki, Y. Baba, M. Inada, A. Nose, H. Suzuki and T. Ota, Bull. Chem. Soc. Jpn., 2011, 84, 1390.

11 H. Miyazaki, T. Ishigaki, H. Suzuki and T. Ota, Bull. Chem. Soc. Jpn., 2014, 87, 838.

12 H. Miyazaki, H. Ichioka, H. Suzuki and T. Ota, Bull. Chem. Soc.Jpn., 2013, 86, 1323.

13 M. Hibino, M. Ugaji, A. Kishimoto and T. Kudo, Solid State Ionics, 1995, 79, 239.

14 H. Miyazaki, K. Tsunomori, H. Suzuki and T. Ota, J. Ceram. Soc. Jpn., 2016, 124, 34.

15 G. Wu, K. Du, C. Xia, X. Kun, J. Shen, B. Zhou and J. Wang, Thin Solid Films, 2005, 485, 284.

16 M. Benmoussa, A. Outzourhit, R. Jourdani, A. Bennouna and E. L. Ameziane, Act. Passive Electron. Compon., 2003, 26, 245.

17 H. Wei, X. Yan, Y. Li, H. Gu, S. Wu, K. Ding, S. Wei and Z. Guo, J. Phys. Chem. C, 2012, 116, 16286.

18 N. Asim, S. Radiman and M. A. Yarmo, Mater. Lett., 2008, 62, 1044. 